This item was submitted to Loughborough's Research Repository by the author.

Items in Figshare are protected by copyright, with all rights reserved, unless otherwise indicated.

\title{
Laser melting functionally graded composition of Waspaloy® and zirconia powders.
}

PLEASE CITE THE PUBLISHED VERSION

PUBLISHER

(C) Springer

LICENCE

CC BY-NC-ND 4.0

REPOSITORY RECORD

Mumtaz, Kamran A., and Neil Hopkinson. 2019. "Laser Melting Functionally Graded Composition of Waspaloy® and Zirconia Powders.”. figshare. https://hdl.handle.net/2134/3543. 
This item was submitted to Loughborough's Institutional Repository by the author and is made available under the following Creative Commons Licence conditions.

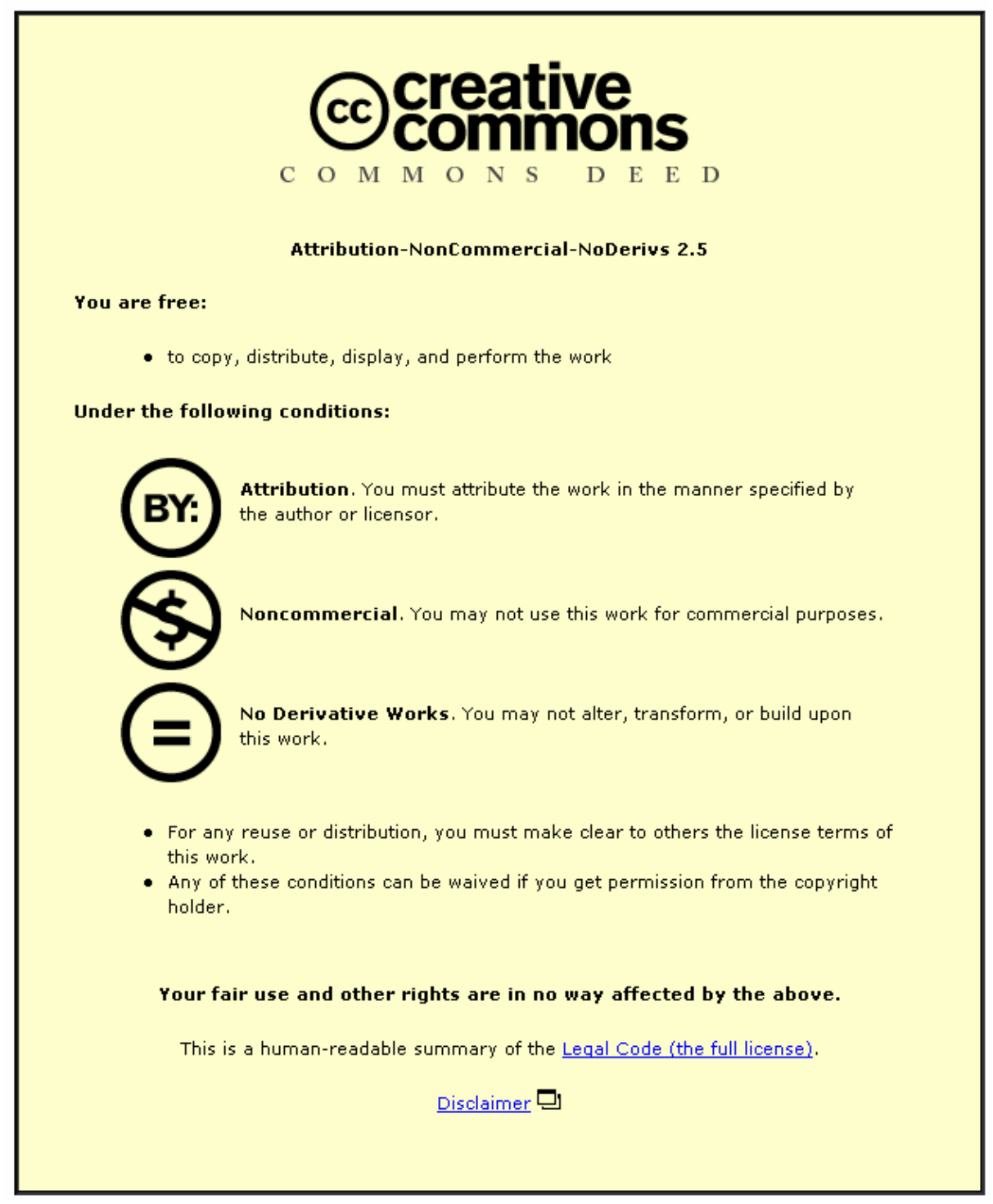

For the full text of this licence, please go to: http://creativecommons.org/licenses/by-nc-nd/2.5/ 
Laser Melting Functionally Graded Composition of Waspaloy ${ }^{\circledR}$ and Zirconia Powders 


\section{Abstract}

An approach for fabricating functionally graded specimens of supernickel alloy and ceramic compositions via Selective Laser Melting (SLM) is presented. The focus aimed at using the Functionally Graded Material (FGM) concept to gradually grade powdered compositions of Zirconia within a base material of Waspaloy ${ }^{\circledR}$. A high power Nd:YAG laser was used to process the material compositions to a high density with gradual but discrete changes between layered compositions. The graded specimens initially consisted of $100 \%$ Waspaloy ${ }^{\circledR}$ with subsequent layers containing increased volume compositions of Zirconia (0-10\%). Specimens were examined for porosity and microstructure. It was found that specimens contained an average porosity of $0.34 \%$ with a gradual change between layers without any major interface defects. 
Keywords : Selective Laser Melting, Functionally Graded Material, Zirconia, Waspaloy, Thermal Barrier Coating 


\section{Introduction}

\section{$1.1 \quad$ Functionally Graded Materials}

Functionally Graded Materials (FGMs) are composites of two or more materials with continuously varying volume fractions. Used as coatings and interfacial zones, they help to reduce mechanical and thermally induced stresses caused by a material property mismatch and can improve bonding strength. FGMs can be designed at varied material gradients to suit a specific application and achieve levels of performance superior to that of homogeneous materials. They can be applied to metals, ceramics and organic composites to generate improved components, they are increasingly being considered in industry for various applications to maximize strengths and integrities of many engineered structures [1]. Functionally graded materials are ideal candidates for applications that experience severe thermal gradients, ranging from thermal structures in aerospace engines to computer circuit boards [2].

An area in which FGMs could play an important role in is the protection of aerospace, automobile and heavy duty industrial utility applications from high temperature environments. Studies related to the improvement in performance of materials for high temperature applications have mainly focused upon the thermally insulating systems of Thermal Barrier Coatings (TBC) [3]. This heat resistant coating is made from materials that have low thermal conductivities such as the ceramic Zirconia. They are applied to the surface of parts or substrates by metallurgical methods of diffusion saturation, electroplating, plasma spraying and Electron Beam Physical Vapor Deposition (EB-PVD) [4]. Initially a bond coat (conventionally MCrALY [5]) is applied to the surface of the application followed by the TBC, this is shown in Fig. 1.

Fig.1 
Nozzle guide vanes (NGV) found within jet engines are a typical application that uses a TBC. These applications experience poor bonding strength between TBC and component when subjected to mechanical and thermal stresses after long term usage. Applications that employ a TBC are typically used within an oxidizing environment and undergo repetitive thermal cycles [6,7]. Thermal stresses are induced by a thermal expansion mismatch between coatings, leading to cracking, delamination and eventual part failure $[8,9,10]$. Significant oxidization problems occur due to the presence of the bond coat resulting in a large coating expansion and generation of high residual stresses at interfaces $[11,12]$.

In an effort to release the residual stresses and improve the properties of conventionally formed heat protective coatings, the concept of FGM has recently been used to alleviate these problems [13]. Functionally grading the protective heat resistant coating within the substrate of the application can be used to alleviate the defects associated with multiple material interfaces $[14,15]]$. A gradual transition in properties through the coating thickness can be established $[16,17]$ and will assist the reduction in residual stresses [18.19] associated with thermal expansion mismatch $[20,21]$. The external part of the specimens resistance to thermal shock cracking can be improved $[22,23]$ as well as a superior bonding between compositions of material allowing for it to become more resistant to delamination $[24,25]$. It has been demonstrated that functionally graded heat resistant coatings also have better resistance to oxidization and a longer lifetime during test conditions than those formed without any type of functional grading [26].

\subsection{Solid Freeform Fabrication}

A great interest has been expressed by industry for the production of FGM components via Solid Freeform Fabrication (SFF) [27]. SFF is family of processes that involve the layer-wise shaping and consolidation of material (e.g. powder, wire). Due to the additive nature of SFF it inherently holds many manufacturing advantages with the potential to produce parts with a high geometric freedom directly from a CAD model. SFF also reduce the time period between 
the initial conceptual design of a part and its actual fabrication. The benefits of using SFF to produce functionally graded parts have led to world-wide research activities [28].

Research has been conducted by Domack et al to test the suitability of different SFF processes in the production of functionally graded Nickel and Titanium parts. Functionally graded parts were formed using Laser Engineered Net Shaping (LENS), flat wire welding and Ultrasonic Consolidation (UC). LENS builds parts by melting metal powder injected into the trajectory of a high power laser beam. Flat wire welding also uses a laser, however it melts wire without the need to create a molten pool of metal on to a substrate. UC is a process in which metal foil under an applied load is fused together using ultrasonic vibration. It was found that functionally graded parts processed using LENS contained macroscopic cracking and significant elemental segregation. Flat wire welding of materials exhibited good mixing between the wire layers but also exhibited cracking. UC parts demonstrated good metallurgical bonding between Nickel and Titanium interfaces. The researchers concluded that all three manufacturing methods require further development before functionally graded parts can be reliably produced [29]. Liu et al also used the LENS process to fabricate functionally graded Titanium Carbide and Titanium ( $\mathrm{TiC} / \mathrm{Ti}$ ) parts. The researchers successfully processed these compositions of material to produce functionally graded $\mathrm{TiC} / \mathrm{Ti}$ crack free parts [30]. Another laser based SFF process known as Selective Laser Sintering (SLS) also uses a laser to melt powders, however the material is processed from a pre-layed powder bed rather then by powder injection. Jepson et al used SLS to produce functionally graded Cobalt and Tungsten Carbide (Co/WC) parts. The grading of these materials would suit applications that require hardness and wear resistance while maintaining a degree of ductility [31].

Selective Laser Melting (SLM) is a tool-less manufacturing process capable of building 3D parts by a consecutive layer by layer production of thin cross-sections. SLM produces parts by selectively melting powder from a powder bed using a scanning focused laser beam, this makes the process extremely similar to SLS. The high power laser beam used within SLM can generate heat capable of fully melting powders. This allows for the direct production of 
high density parts without any breaks in the build cycle. The SLM process has great potential within the manufacturing of specialized functional applications [32].

Limited research has been conducted using SLM to produce functionally graded parts. Research has included functionally graded Tungsten Carbide/Tool Steel parts [33] and Tool Steel/Copper parts [34]. Literature suggests that no research has used SLM to produce functionally graded nickel alloy and ceramic parts

\subsection{Benefits of SLM functionally graded parts}

The use of SLM to fabricate functionally graded parts would allow for the control in composition of material within each layer and precise regulation of the FGM gradient. Gradually changing the composition of material from metal to ceramic could allow for a TBC to be applied to a component without the requirement of a bond coat. This in turn should reduce the residual stress build up between TBC and application. Combining these technologies could extend the scope and capabilities of laser-assisted manufacturing by reducing production costs improving the performance and durability of functionally graded parts.

Waspaloy ${ }^{\circledR}$ is a high temperature supernickel alloy that is typically used within jet engine components. Zirconia is a ceramic that is most commonly used to provide a TBC for these components. This investigation focused on using an Nd:YAG laser to fabricate by SLM functionally graded compositions of these materials. The laser processing parameters used had been specifically optimized for the production of high density crack free Waspaloy ${ }^{\circledR}$ parts [35]. 


\section{Experimental Methodology}

\subsection{Setup}

A high power 550W Nd:YAG pulsed laser (GSI Lumonics JK701H) operating at a wavelength of $1.06 \mu \mathrm{m}$ was used. The laser beam had a spot diameter of $0.8 \mathrm{~mm}$. The beam was carried through a fibre optics delivery system and was installed on a 4-axis CNC controlled machine. Powder layers were deposited in one direction by means of a hopper that traversed across the powder bed. Argon was used as a shield gas to prevent parts from oxidization. Parts were built on $43 \mathrm{~mm} \times 30 \mathrm{~mm} \times 4 \mathrm{~mm}$ steel substrates. The experimental setup is shown in Fig. 2.

Fig. 2

\section{$3 \quad$ Powder Properties}

Two powders were used within this investigation, a supernickel alloy Waspaloy ${ }^{\circledR}$ shown in Fig.3(a) and a partially stabilized ceramic Zirconia with 7-9\% yttria (PSZ) shown in Fig.3(b)

The Waspaloy ${ }^{\circledR}$ powder had a mean particle size of $63 \mu \mathrm{m}$. In its solid form it has excellent strength at high temperature and good resistance to corrosion and oxidization. This material has a melt temperature of around $1330-1360^{\circ} \mathrm{C}$. Waspaloy ${ }^{\circledR}$ has been used for aerospace and gas turbine engine components as well as other miscellaneous engine hardware [36]. The chemical composition of Waspaloy ${ }^{\circledR}$ is shown in Table 1

Fig. 3

Table $1[36]$ 
The PSZ powder had a mean particle size of $0.5 \mu \mathrm{m}$. The yttria content stabilizes the ceramic at higher temperatures, avoiding phase transition and increasing the spallation life of the ceramic. The material's melting temperature is around $1350-1500^{\circ} \mathrm{C}$, its chemical composition is shown in Table 2. Fig. 3(b) shows regions of the PSZ powder that has agglomerated, these agglomerates are comparable in size to that of the Waspaloy ${ }^{\circledR}$ powder.

Table $2[37]$

\subsection{Specimen Preparation and Processing}

Four compositions of material were used, the first consisted of $100 \%$ Waspaloy ${ }^{\circledR}$ followed by increasing additions of PSZ. Each powder blend was mixed by volume fraction, placed in a ceramic container and blended for six hours. The volume fractions used are shown in Table 3 , the SEM images of these mixed composition are shown in Fig. 4

Table 3

Fig. 4

The placement of these powered compositions is shown in Fig. 5. The layers were graded in the $z$-axis and comprised a total of eight $0.4 \mathrm{~mm}$ thick layers with the PSZ content changed stepwise from 0-10\% volume. The first two layers consisted of $100 \%$ Waspaloy ${ }^{\circledR}$. The third and the fourth layers contained volume compositions of $99 \%$ Waspaloy ${ }^{\circledR}$ and $1 \%$ PSZ. Layers five and six consisted of 95\% Waspaloy ${ }^{\circledR}$ and 5\% PSZ. Layers seven and eight consisted of $90 \%$ Waspaloy ${ }^{\circledR}$ and $10 \%$ PSZ.

Fig. 5 


\subsubsection{Fabricating Functionally Graded 25x5mm specimens}

Initial specimens were $25 \mathrm{~mm}$ in length, $5 \mathrm{~mm}$ in width and consisted of eight $0.4 \mathrm{~mm}$ layers with the functionally graded compositions shown in Fig. 5.

Five test specimens were made and analysed under Scanning Electron Microscopy (SEM) and Energy Dispersive X-ray Spectroscopy (EDS) analysis. These test specimens were observed for grading of layers and material segregation.

In previous work a refill scanning strategy that had been successfully developed to produce high density steel parts using SLM was used for processing these specimens. This scanning and refill strategy is shown in Fig. 6 [33]. Scans 1a, 2a, 3a etc. were initially performed followed by a refill strategy $1 b, 2 b, 2 c$ to complete the layer.

Fig. 6

Parts were fabricated using optimized laser processing parameters developed in previous work to fabricate high density Waspaloy ${ }^{\circledR}$ specimens [35], these are shown in Table 4.

Table 4

\subsubsection{Fabricating Functionally Graded 10x10mm specimens}

10x10mm blocks were created using a varied scanning strategy. The scanning strategy used was similar to that employed for processing the $25 \mathrm{~mm} \times 5 \mathrm{~mm}$ (section 3.1.1). However, each successive layer was scanned perpendicular to the previous. It was proposed that the use of this scanning strategy would improve the grading of layers and remove any periodic wave structure within the part. This should help avoid the formation of interconnected porosity [38] and prevent layer delamination. The cross-hatching technique and specimen dimensions are shown in Fig. 7. 
Fig. 7

The same laser processing parameters used for fabricating the $25 \times 5 \mathrm{~mm}$ specimens were also used in the construction of the $10 \times 10 \mathrm{~mm}$ specimens. Once again five test specimens were produced, these specimens were observed for geometrical distortions, the occurrence of porosity and general microstructure including grading of layers. Standard metallographic techniques were used for the preparation of specimens by SEM analysis. An etching solution of $\mathrm{CuSO}_{4}$ was used to reveal the microstructure. The porosity of the specimen was measured using Image Tool [39], a PC software which visually analyses a specimen's cross section and determines it's porosity.

\section{$4 \quad$ Results}

\subsection{Functionally Graded $25 \times 5 \mathrm{~mm}$ specimen}

The $25 \times 5 \mathrm{~mm}$ functionally graded specimen was cross-sectioned and viewed using SEM, shown in Fig. 8. This specimen contained an average porosity of $0.45 \%$. The variation in material composition between the layers is shown with a change in colour. The layers lighten in colour as the PSZ content is increased. Layers with 5-10\% PSZ contain dark segments or bands that could be a result of alloy or ceramic segregation. The locations of each dark segment appear at interlayer boundaries or where the laser initially strikes the materials.

As the volume percentage of Waspaloy ${ }^{\circledR}$ decreased and PSZ increased, there was less likelihood of full melting occurring due to PSZ having a higher melting temperature than Waspaloy ${ }^{\circledR}$. Further to this the laser processing parameters used were specifically optimized for high density processing of $100 \%$ Waspaloy ${ }^{\circledR}$ and not for mixed composition of high temperature ceramic. 
The composition within the final layers may not have been fully homogenized within the mixture of materials. In order to determine the content of darker or lighter patches specific regions were subjected to EDS

Fig. 8

\subsubsection{Energy Dispersive X-ray Spectroscopy Analysis}

A further magnified image of the $25 \times 5 \mathrm{~mm}$ specimen within the region containing $1 \%-5 \%$ PSZ is shown in Fig. 9. A number of dark patches were observed with one highlighted in region 1. A EDS analysis of the dark area and lighter area within this region was analysed, the results are shown in Fig. 10.

Fig. 9

Fig. 10

The lighter region in Fig. 9(1a) was analysed and revealed it contained the same elements present within Waspaloy ${ }^{\circledR}$ shown in Fig 10(a). The darker area in Fig. 9(1b) consisted mostly of PSZ with small elements of titanium and aluminium, shown in Fig. 10(b). This shows that the PSZ particles accumulated in one particular area with only small amounts of Waspaloy ${ }^{\circledR}$ elements (titanium and aluminium). This could be a result of the original agglomeration of PSZ observed in Fig. 3(b). The small particle size of PSZ may make it difficult to break up agglomeration, separate and distribute particles within a Waspaloy ${ }^{\circledR}$ mixture causing isolated patches of PSZ to form.

The difference in material properties of Waspaloy ${ }^{\circledR}$ and PSZ may cause these materials to react differently within the melt pool. The heat generated from the centre of the laser interaction zone lowers the density of heated powders. Cooler powders at the edge of the 
Heat Affected Zone (HAZ) will have higher densities. Therefore gravity will cause molten material at the edge of the HAZ to sink within the melt pool due to gravity (Buoyancy force). Different material densities will cause variations in the movement of material within the melt. This may explain why there is segregation of materials within layers containing higher PSZ content (Fig. 8). Another factor that may contribute to material segregation is surface tension. The surface tension of a material reduces with increasing temperature, cooler material at the edge of a HAZ will pull material from the centre of the HAZ to the edge (Marangoni convection). Waspaloy ${ }^{\circledR}$ conducts heat better than PSZ (subsequently melting over a larger $\mathrm{HAZ}$ ) due to it having a higher thermal conductivity. There will therefore be a variation in movement of materials within melt due to surface tension forces.

Despite the segregation of materials, the solidification structure around the embedded PSZ shows good wettability, resulting in a dense structure. This scenario is certainly preferable to experiencing defined voids around the agglomerated PSZ due to poor wetting.

\subsection{High Density 10x10mm Functionally Graded Specimen}

A fabricated $10 \times 10 \mathrm{~mm}$ specimen can be seen in Fig. 11. The cross-sectioned specimen viewed under an SEM microscope is shown in Fig. 12.

Fig. 11

Fig. 12

The top layer of the specimens is not completely flat, it is assumed that the scanning strategy as well as the differences between material properties of Waspaloy ${ }^{\circledR}$ and PSZ contributed to the unevenness of the top layer. As mentioned in section 4.1 the differences in material properties may have caused an alloy ceramic segregation. The placement and movement of material within the melt pool could have affected the formation of the top layer. The extreme ends of the block suffer from bulges or elevated edges that rise above the rest of the 
specimen. This is attributed to the scanning strategy initially processing the outer profile of the specimen. A large amount of material will initially be drawn into the melt pool, this leaves less material for subsequent scans within the same layer. Another factor connected to the availability of loose powder is the presence of existing solidified material.

The functionally graded specimens were crack free and contained an average porosity of $0.34 \%$. The porosity was more prevalent within layers containing higher compositions of PSZ.

The layers of different material composition appear to grade more evenly than that seen in Fig. 8, producing less discrete changes in layer boundaries. The dark bands that were predominate in the previous specimen are far less recognizable, indicating an improved and more even distribution of Waspaloy ${ }^{\circledR}$ and PSZ particles. The presence of PSZ is noticeable with increasing volume of PSZ that appear to lighten the contrast of layers. The four compositions of material result in four varying contrasts throughout the layer, occurring at $0.5 \mathrm{~mm}$ intervals along the $z$-axis.

The improved grading of Waspaloy ${ }^{\circledR}$ and PSZ may have been a result of the cross-hatching strategy breaking up any unevenly distributed and repetitive heat build-up along the layer causing segregation of materials due to differences in material properties. Research has shown that porosity can propagate through subsequent layers forming an interconnected void. Cross-hatching can eliminate interconnected porosity and maintain a level of uniformity throughout the layer [36]. This is demonstrated by the fact that the $25 \times 5 \mathrm{~mm}$ functionally graded specimen was produced without cross-hatching and contained porosity $0.45 \%$, whereas the $10 \times 10 \mathrm{~mm}$ sample was fabricated using cross-hatching and held a lower porosity of $0.34 \%$

Fig. 13 shows the cross-sectioned specimen at a higher magnification, little transition between the different material compositions was observed. The exact location and morphology of PSZ was not visible due to low magnification. However initial observation and comparison of specimen cross-sections generally indicates an improvement within the 
grading and distribution of materials. This is a promising feature for high temperature applications as it may alleviate the problems associated with defined interfaces between two different materials. These problems include thermal expansion mismatch, high residual stresses, cracks and possible delamination.

Region one in Fig. 13 shows very fine precipitates of gamma prime with angles between the grain boundary. This very fine or amorphous microstructure may be a consequence of the rapid cooling rate near the top of the specimen.

Region two in Fig. 13 shows an area where a small amount of porosity is present. The grain sizes appear to increase in size possibly due to a longer cooling period as result of re-melting and slow processing speed.

Region three in Fig. 13 shows a columnar grain structure that aligns along the direction of the substrate due to directionally cooling through the steel substrate.

Fig. 13

It has been shown that despite stepwise stacking, the microstructure and distribution of metal and ceramic elements gradually change without distinct observable boundaries throughout the layers.

\section{Conclusion}

Using SLM to produce functionally graded parts has proven successful when grading small amounts of ceramic within a nickel alloy. It has been demonstrated that despite stepwise stacking, the microstructure and the distribution of material elements are gradually changed without distinct boundaries between layers when a cross-hatching scan strategy is used. 
Increasing compositions of 1\%,5\% and 10\% PSZ were functionally graded with Waspaloy ${ }^{\circledR}$ and processed using optimized laser parameters. Initially a $25 \times 5 \mathrm{~mm}$ functionally graded specimen was fabricated to a density of $99.55 \%$. This contained dark bands or regions that may have been caused by an alloy or ceramic segregation. EDS analysis found that small areas or patches of agglomerated material were compositions of PSZ. This segregation of material may have been due to the difference in Waspaloy ${ }^{\circledR}$ and PSZ material properties. This could have caused a variation in movement of material within the melt pool due to the Buoyancy and Marangoni affects. The PSZ compositions within the layers showed good wettability when embedded amongst solidified Waspaloy ${ }^{\circledR}$ and therefore good bonding.

The $10 \times 10 \mathrm{~mm}$ specimen fabricated using a cross-hatching scanning technique had an average density of $99.66 \%$. The specimen experienced geometric unevenness and tended to bulge at its edges due to large amounts of material being pulled into the melt of initial scans. However the cross-hatching scanning technique was found to improve the grading of material compositions making interlayer boundaries less discrete. Initial analysis suggests that the segregation and agglomeration of PSZ experienced within earlier specimens had been significantly reduced as a result of the modified scanning strategy.

The laser's heat distribution when processing compositions of material from a powder bed is a significant factor. It affects the part porosity, location of material within a layer and has the potential to generate uniformity within functionally graded parts.

Early tests suggest that functionally graded compositions of Waspaloy® and PSZ can be processed using SLM to produce high density crack free parts. The functionally graded layers are less likely to experience severe thermal expansion mismatch and delamination. Whether fabrication using the SLM process improves the performance of the component and avoids premature failure can only be determined after further advanced testing and analysis. 


\section{$\underline{\text { References }}$}

[1] GU Y., NAKAMURA T., PRCHLIK L., SAMPATH S., WALLACE J., Micro-indentation and inverse analysis to characterize elastic- plastic graded materials, Materials Science and Engineering A, v 345, n 1-2, Mar 25, 2003, p. 223-233.

[2] ABOUDIA J., PINDERAB M.J., ARNOLD, S.M., Higher-order theory for functionally graded materials, Composites: Part B 30 (1999) p.777-832.

[3] POLAT, A., SARIKAYA, O., CELIK, E., Effects of porosity on thermal loadings of functionally graded Y2O3-ZrO2yNiCoCrAlY coatings, Materials and Design 23 (2002) p.641644.

[4] MOVCHAN B.A., YU K., Graded thermal barrier coatings, deposited by EB-PVD, Surface \& Coatings Technology 188-189 (2004) p.85- 92.

[5] QUADAKKERS W.J., SHEMET V., SEBOLD D., ANTON R., WESSEL E., SINGHEISER L., Oxidation characteristics of a platinized MCrAlY bond coat for TBC systems during cyclic oxidation at 1000 C, Surface \& Coatings Technology 199 (1) (2005), p.77-82.

[6] MILLER R.A., LOWELL C.E., Failure Mechanisms of Thermal Barrier Coatings Exposed to Elevated Temperatures, Thin Solid Films 95, no.3 (1982) 265.

[7] MILLER, R.A, BERNDT, C.C, Performance of thermal barrier coatings in high heat flux environments Thin Solid Films 119, no.2 (1984) 195.

[8] GILL S.C., CLYNE T.W., Stress distributions and material response in thermal spraying of metallic and ceramic deposits, Metallurgical Transactions 21B (1990) 377.

[9] FERRARI, M., LUTTEROTTI, L., Thermal stresses in bi-coated structures, Journal of Engineering Mechanics 118, no. 9 (1992) 1928.

[10] SINGHEISER L., STEINBRECH L., QUADAKKERS W.J., Herzog R., Failure aspects of thermal barrier coatings, Material at high Temperatures 18 (4) (2001) p.249 -259.

[11] Nomura N., Gasik M., Kawasaki A., Watanabe R., Functionally Graded Materials 2000, Proc. 6th International Sypm., Functionally Graded Materials, Colorado, USA, Sept 10-14, Ceramic Transactions, Vol. 114, (2000) p. 233.

[12] LIMARGA, A.M., WIDJAJA, S., YIP, L.K., Microstructural Characterizations of PlasmaSprayed Zr)2/Al2O3 Thermal Barrier Coatings as related to Oxidation Behaviour, The International Journal of Modern Physics B 16 (2002) 233. 
[13] CHOULES, B.D KOLINI, K. Architecture of functionally graded ceramic coatings against surface thermal fracture, Journal of Engineering Materials and Technology Transactions of the ASME 118, no.4 (1996) 522.

[14] SASAKI, M., and HIRIRAI, T., Cent. Mem. Iss. Ceram. Soc. Jpn 99 (1991) 1002.

[15] WATANABE, R., TAKAHASHI, H., TAMURA, M., SHIOTA, I., YOSHIDA, T. and KURINO, T., Functionally Gradient Materials, FGM Forum Japan (1993) p.1-10.

[16] KHOR, K.A., DONG, Z.L., GU, Y.W., Plasma sprayed functionally graded thermal barrier coatings Mater. Lett. (1999), no.38 p.437.

[17] DONG, ZL, KHOR, KA, GU, Y.W. Microstructure formation in plasma-sprayed functionally graded NiCoCrAIY/yttria-stabilized zirconia coatings, Surf. Coat. Tech. V.113, 1999, p.181.

[18] JUNG, Y.H., CHOI, S.C., Residual stress and thermal properties of zirconia/metal (nickel, stainless steel 304) functionally graded materials fabricated by hot pressing, Journal of Materials Science 32 (1997) p.3841-3850.

[19] DEMIRKIRAN, A.S., ELIK, E., AVCI, E., Evaluation of functionally gradient materials after thermal shock, Proceedings of the Fifth International Fracture Conference, (10) (2001) p.1341-1344.

[20] DEMIRKIRAN, A.S., AVCI, E., Evaluation of functionally gradient coatings produced by plasma-spray technique, Surf Coatings Tech. (1999)116-119, p.292 -295.

[21] DEMIRKIRAN, A.S., ELIK, E., AVCI, E., Oxidation of functionally gradient materials, Proceedings of the Fifth Combustion Symposium, Bursa (Turkey): July 21-23, (1997) p.543551.

[22] KAWASAKI, A., WATANABE, R., YUKI, M., NAKANISHI, Y., ONABE, H., Effect of microstructure on thermal shock cracking of functionally graded thermal barrier coatings studied by burner heating test, Materials Transactions, JIM 37 (4) (1996) 788.

[23] KHOR, K.A., GU, Y.W., Thermal properties of plasma-sprayed functionally graded thermal barrier coatings, Thin Solid Films 372 (2000) p.104.

[24] KOKINI, K., DEJONGE, J., RANGARAJ, S.V., BEARDESLY, B.M., Thermal fracture in functionally graded thermal barrier coatings with similar thermal resistance, Surf. Coat. Tech. (2002) p.223-231. 
[25] YONUSHONIS, T. Proceedings of the Workshop on Thermal Barrier Coatings, NASA Conference Publication 3312 (1995) p.235.

[26] GASIK, M., KAWASAKI, A., KANG Y.S., Optimization of FGM TBC and their thermal cycling stability, Material science forum vol. 492-49 (2005) p. 9-14.

[27] WOHLERS, T., Wohlers Report 2003 Rapid Prototyping and Tooling State of the Industry, Annual Worldwide Progress Report.

[28] CHERRADI, N., KAWASAKI, A., GASIK, M., Worldwide trends in functional gradient materials research and development. Comp. Eng v. 4 (1999) p.883-94.

[29] DOMACK, M.S., BAUGHMAN, J.M., Development of nickel-titanium graded composition components, Rapid Prototyping Journal 1(11) (2005) p.41-51.

[30] LIU, W., DUPONT, J. N., Fabrication of functionally graded TiC/Ti composites by Laser Engineered Net Shaping, Scripta Materialia, 9(48) (2003) p.1337-1342

[31] JEPSON, L., BEAMAN, J.J., BOURELL, D.L., WOOD, K.L., SLS processing of functionally graded materials, SFF Symposium Proceedings (1997) p.67-79.

[32] KRUTH, P., FROYEN, L., VAERENBERGH, J.V., MERCELIS, P., ROMBOUTS, M., LAUWERS, B., Selective laser melting of iron-based powder, Journal of Materials Processing Technology, 149(1-3) (2004), p.616-622.

[33] SU W. N., Layered Fabrication of Tool Steel and Functionally Graded Material with a Nd:YAG Pulsed Laser, Phd Thesis, Loughborough University (2002).

[34] BEAL, V.E., ERASENTHIRAN, P., HOPKINSON, N., DICKENS, P., AHRENS, C.H., Int J Adv Manuf Technology, (30) (2006) p. 844-852.

[35] MUMTAZ, K., HOPKINSON, N., ERASENTHIRAN, P., High Density Selective Laser Melting of Waspaloy®, SFF Symposium Proceedings (2006) p.220-232.

[36] Special Metals, "Waspaloy", www.SpecialMetals.com, as on $1^{\text {st }}$ August 2006.

[37] Mel chemical, "Zirconia", www.mel-chemical.com, as on $1^{\text {st }}$ August 2006.

[38] MORGAN, R.H., PAPWORTH A.J., SUTCLIFFE C., FOX P., O'NEILL W., High density net shape components by direct laser re-melting of single-phase powders, Journal of material science 37 (2002) p.3093 - 3100 .

[39] UTHSCA, The University of Texas Health Science Center at San Antonio, ImageTool Version 3.0. 


\section{$\underline{\text { Tables }}$}

Table $1 \quad$ Waspaloy ${ }^{\circledR}$ Nominal Weight Composition in percent [30]

Table 2 Partially stabilized ceramic Zirconia with 7-9\% yttria weight composition [31]

Table $3 \quad$ Volume compositions of material

Table $4 \quad$ Optimized processing parameters for processing Waspaloy ${ }^{\circledR}$ 


\section{Figure Legends}

Fig.1 Cross-sectional view of a TBC, bond coat and application substrate

Fig.2 Experimental Setup

Fig. 3 Micrograph of Waspaloy® (A) \& PSZ particles (B)

Fig. 4 Micrograph images of (a) $99 \%$ Waspaloy ${ }^{\circledR} 1 \%$ PSZ, (b) $95 \%$ Waspaloy ${ }^{\circledR} 5 \%$ PSZ, (c) $90 \%$ Waspaloy ${ }^{\circledR} 10 \%$ PSZ

Fig. 5 Layers of functionally graded composition of Waspaloy® and PSZ graded in the zaxis

Fig. 6 Plan view of optimized scan and refill strategy

Fig. 7 Illustration of layer cross hatching technique and specimen dimensions

Fig. 8 Cross-sectional image of 25x5mm layered FGM specimen

Fig. 9 Micrograph characteristics of layers of 1\% and 5\% PSZ layers

Fig. 10 EDS analysis results for region 1A \& 1B

Fig. 11 Functionally graded 10x10mm specimen before and after cross-sectioning

Fig. 12 Cross-sectional view of $10 \times 10$ specimen

Fig. 13 Micrographs characteristics of specimen of FGM 